\title{
Fryns syndrome: a variable MCA syndrome with diaphragmatic defects, coarse face, and distal limb hypoplasia
}

\section{J P FRYNS}

From the Centre for Human Genetics, University of Leuven, Belgium.

The name Fryns syndrome was given by Lubinsky et $a l^{1}$ to "a new variable multiple congenital anomaly syndrome" reported by us in $1979 .^{2}$ We first detected this syndrome in two female sibs who presented with cloudy corneae, diaphragmatic defects, and distal limb deformities. ${ }^{2}$ The parents were. unrelated and normal and chromosome investigation showed normal karyotypes in the parents and in one child investigated. In both children the condition was lethal before birth and pregnancy ended around 30 weeks. We therefore assumed that this

Received for publication 9 January 1987. Accepted for publication 20 January 1987. was a new lethal syndrome, and the assumption was confirmed when we found another instance, again in a stillborn child. ${ }^{3}$ Since then, other authors ${ }^{14-6}$ have made similar findings.

\section{Clinical findings}

A combination of the following findings should lead to the clinical diagnosis of this MCA syndrome.

(1) Hydramnios in the second trimester of pregnancy with normal fetal growth.

(2) Distinct craniofacial features (figs 1 and 2) with coarse face, broad, flat nasal bridge, large nose with

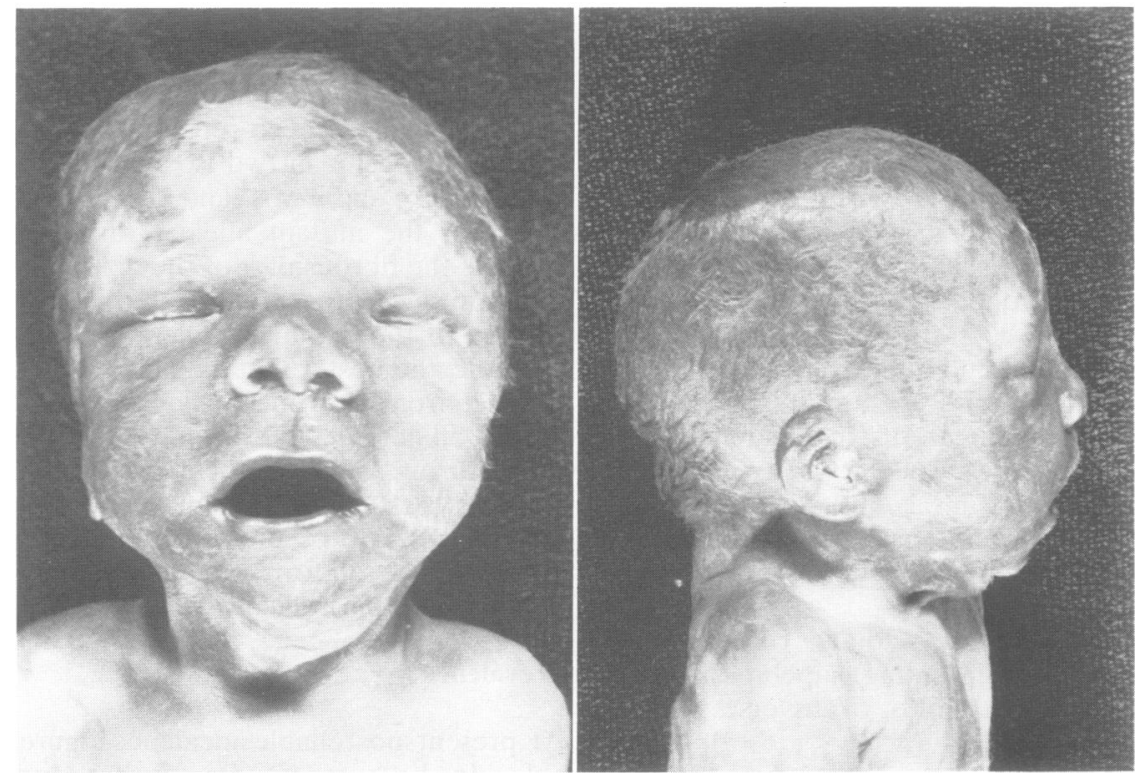

FIG 1 The characteristic craniofacial appearance with coarse face, broad, flat nasal bridge, and micrognathia. 


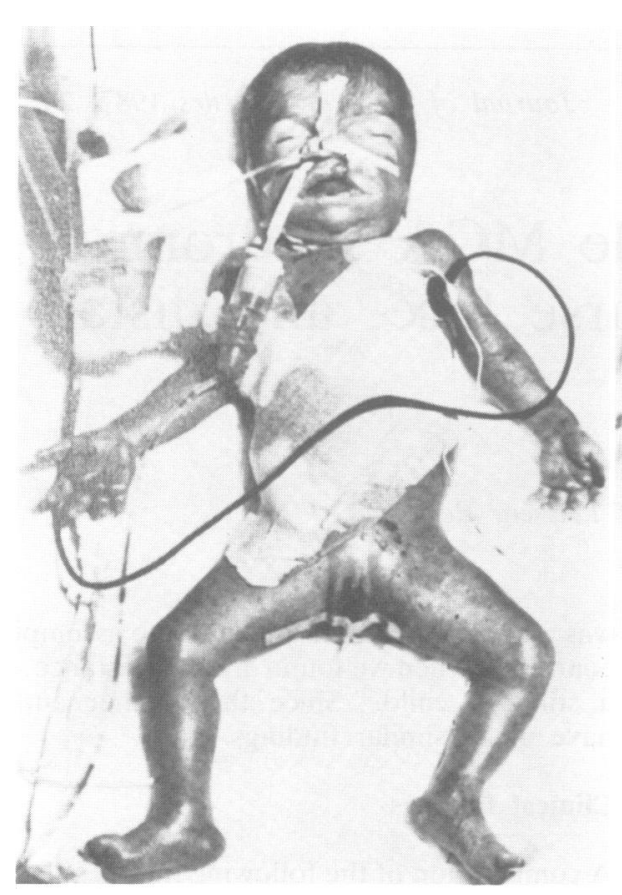

anteverted nostrils, short upper lip, macrostomia, cleft lip/palate, microretrognathia, and poorly shaped auricles with attached earlobes.

(3) Narrow thorax and hypoplastic, widely spaced nipples.

(4) Distal limb hypoplasia with brachytelephalangy, hypoplastic or absent nails, and rudimentary development of terminal (and middle) phalanges most pronounced on rays IV and V (fig 3 ).

(5) Internal malformations mainly include: diaphragmatic defects (aplasia of posterolateral parts) with primary or secondary lung hypoplasia (see pathogenesis) (fig 4); gastrointestinal anomalies including malrotation and non-fixation and duodenal or multiple atresias; genitourinary malformations with bicornuate uterus in the female.

(6) Associated anomalies. The variability in clinical expression in this syndrome is unknown at present because only eight patients have been reported so far. The following anomalies seem to be found in less than $50 \%$ of cases.

External malformations: cloudy corneae and microphthalmia, upward slanting palpebral fissures, short neck with nuchal folds, transverse palmar creases, and club foot.

Internal malformations: renal dysplasia and cortical cysts, cerebral malformations including Dandy-

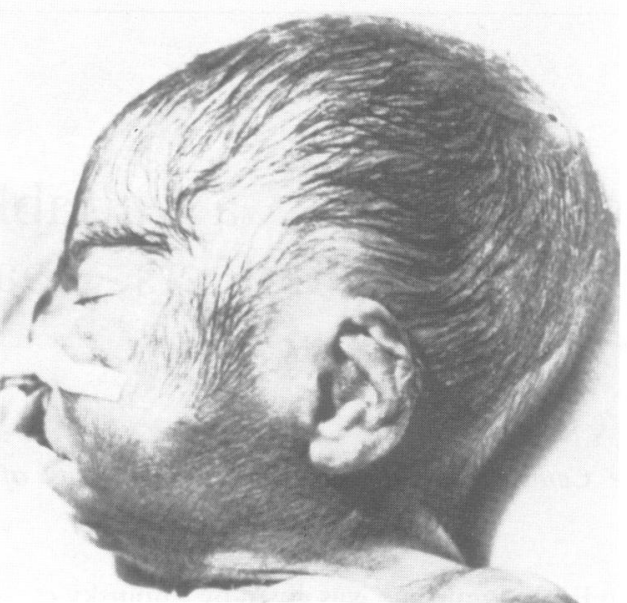

FIG 2 The craniofacial anomalies in Fryns syndrome. The excessive lanugo, most pronounced in the frontal and temporal regions, is another characteristic finding.

Walker cyst, and multiple cerebellar glioneura $\vec{\Phi}$ heterotopias.

\section{Aetiology and pathogenesis}

Autosomal recessive inheritance is most likely. Tw pairs of sibs have been reported ${ }^{12}$ and the parent? were first cousins in two isolated patients reported by Meinecke and Fryns ${ }^{4}$ and Schinzel. ${ }^{6}$ The primare defect of the mutant allele is unknown. In most patients the fibrous part of the diaphragm, originat ing from the septum transversum, and the musculap portion of the diaphragm were well developed. I느. contrast, the posterolateral parts of the diaphragm derived from the plicae pleuroperitoneales, were absent bilaterally. The formation of these plicae is induced by the outgrowth of both lungs. Thiso suggests that lung hypoplasia with absence o lobulation might be the primary event, with secone dary absence of formation and outgrowth of thథ plicae pleuroperitoneales.

\section{Prevalence}

At present no reliable incidence figures are avail 8 able. In Leuven, we found three patients in consecutive series of 900 perinatal necropsies and 


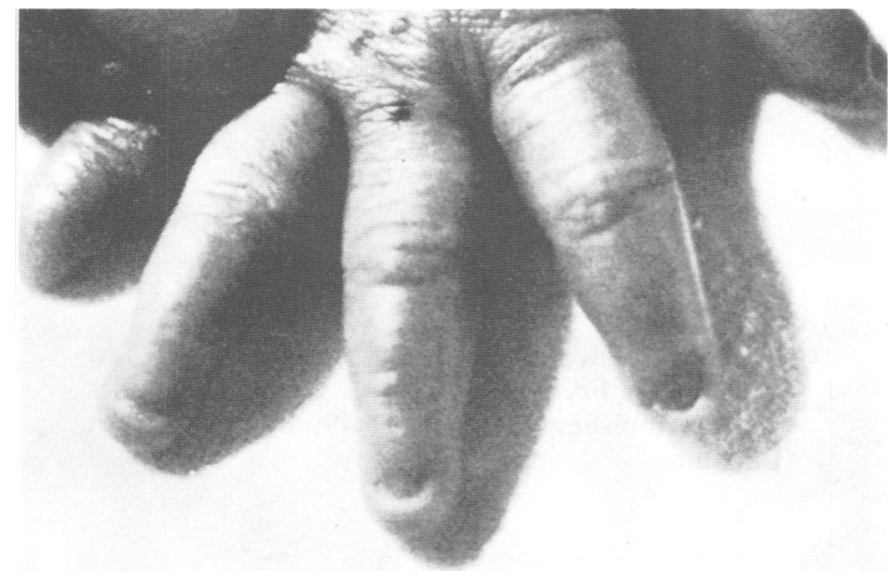

FIG 3 Hypoplastic terminal phalanges of all fingers and toes

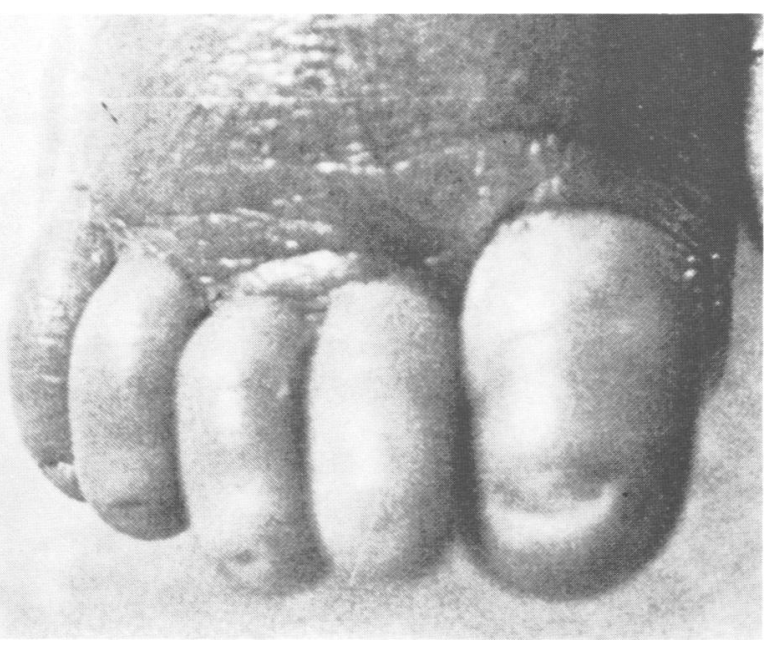

FIG 4 Diaphragmatic defects with hypoplasia of the posterolateral parts, severe lung hypoplasia (lungs indicated by arrows), and herniation of abdominal organs into the thoracic cavity.

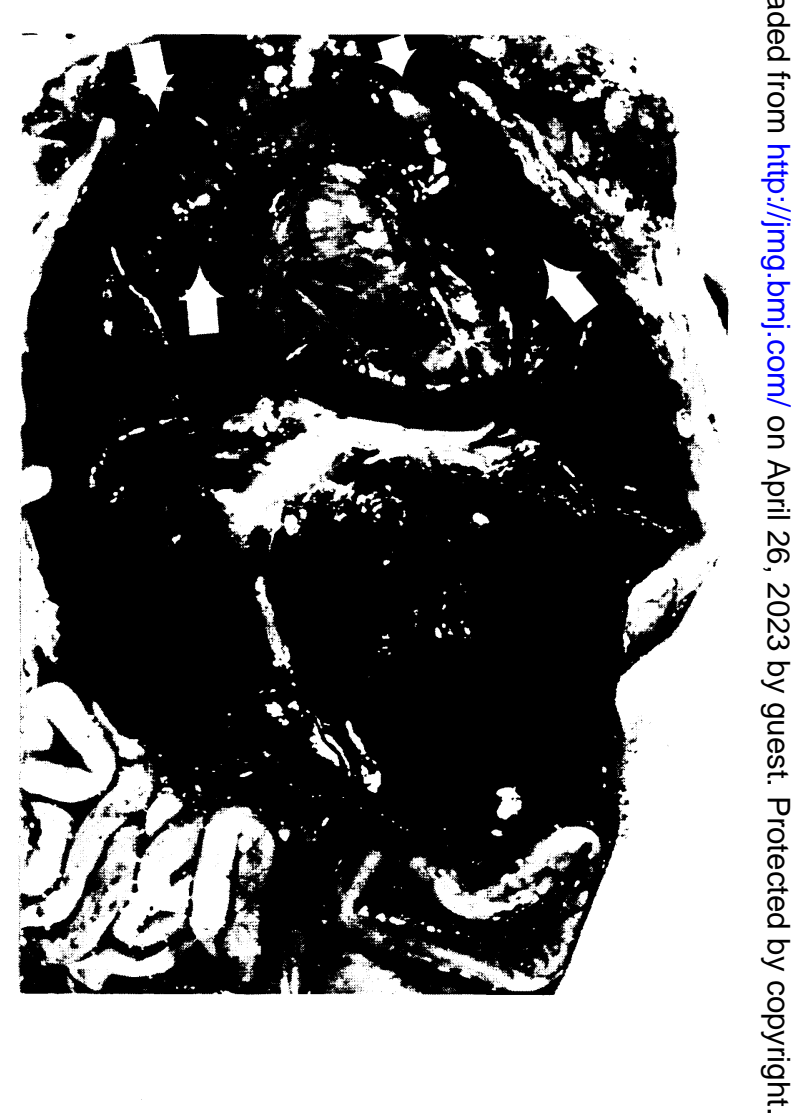
with small nails. 
Dr S Aymé (personal communication, 1986) found three newborns with this syndrome in a series of 850 perinatal necropsies. Long term prognosis seems to be poor and limited by the presence of severe lung hypoplasia. All patients died in the first weeks of life.

\section{References}

' Lubinsky M, Severn C. Rapoport JM. Fryns syndrome: a new variable multiple congenital anomaly (MCA) syndrome. Am J Med Genet 1983;14:461-6.

2 Fryns JP. Mocrman P. Goddecris P. Bossuyt C. Van den Berghe H. A new lethal syndrome with cloudy corneac. diaphragmatic defects and distal limb deformitics. Hum Genet 1979:50:65-70.
${ }^{3}$ Goddeeris P, Fryns JP, Van den Berghe H. Diaphragmatic $\stackrel{\mathbb{P}}{+}$ defects, craniofacial dysmorphism, cleft palate and distal limb $\Rightarrow$ deformities. A new lethal syndrome. J Genet Hum 1980;28: 57-60.

${ }^{4}$ Meinecke P, Fryns JP. The Fryns syndrome: diaphragmatic defects, craniofacial dysmorphism, and distal digital hypoplasia. Clin Genet 1985;28:516-20.

5 Young ID, Simpson K, Winter RM. A case of Fryns syndrome. J Med Genet 1986;23:82-4.

6 Schinzel A. Catalogue of unbalanced chromosome aberrations in man. Berlin, New York: Walther de Gruyter, 1984.

Correspondence and requests for reprints to Pro- $\vec{\omega}$ fessor J P Fryns, Centre for Human Genetics, UZ Gasthuisberg, Herestraat 49, B-3000 Leuven, Belgium. 